International Journal of Linguistics, Literature and Translation

ISSN: 2617-0299 (Online); ISSN: 2708-0099 (Print)

DOI: 10.32996/ijltt

Journal Homepage: www.al-kindipublisher.com/index.php/ijltt

\title{
Feasibility of Digital Multimedia Language Labs for Interpreting Instruction as Perceived by Interpreting Instructors in Saudi Arabia
}

\author{
Prof. Reima Al-Jarf 8 (D) \\ Full Professor of ELT, ESP and Translation, King Saud University, Riyadh, Saudi Arabia \\ $\triangle$ Corresponding Author: Prof. Reima Al-Jarf, E-mail: reima.al.jarf@gmail.com
}

ARTICLE INFORMATION

Received: March 01, 2021

Accepted: April 17, 2021

Volume: 4

Issue: 4

DOI: $10.32996 /$ ijllt.2021.4.4.8

\section{KEYWORDS}

Multimedia language lab, language lab, digital lab, compute lab, interpreting teaching, interpreting instruction, interpreting instructors

\section{ABSTRACT}

The College of Languages and Translation (COLT) prepares translators and interpreters. Some of the courses that the students take are language courses such as listening, speaking, reading, writing, vocabulary, grammar, and 4 types of interpreting courses (simultaneous, consecutive, liaison and sight). COLT has installed 4 multimedia language labs (MLLs) currently used for teaching listening courses, in addition to interpreting courses. Each MLL consists of a teacher's station and 40 student stations each with a computer, headsets, and an audio box. The MLL software consist of XClass, a multimedia classroom management software, a Digital Language Lab Software (DLL) software for improving the students' oral listening skills, and WaveLab Mastering and Audio Editing Software. The presentation aims to find out whether the MLL is feasible for interpreting instruction and factors that affect lack of utilization of MLLs in interpreting instruction at COLT based on the instructors' views. A sample of 10 interpreting instructors and an IT specialist was interviewed. It was found that only $20 \%$ use the MLL in interpreting instruction (simultaneous and sight interpreting). By contrast, $80 \%$ use the MLLs as a classroom, use the speakers, text on a flash drive and MP3 players. They believe that MLLs are not suitable for teaching consecutive and liaison interpreting. They reported hardware and software problems, instructor-related, student-related, and technical support issues. The study concluded that normalization and attitude change towards new technology, hands-on practice, and availability of technical support on site are crucial in adapting the MLLs to interpreting instruction. The study reports results and some recommendations.

\section{Introduction}

Since the 1950's, language labs have been popular in many countries for developing language skills of L2 students learning a second/foreign language (L2). Due to technological advancements of all kinds and in all disciplines, multimedia labs have become available in many parts of the world. A multimedia lab (MLL) is a multi-computer teaching facility dedicated to integrating creative technology in teaching and learning. It contains software and equipment for the production of sound, video, animation, graphics, and 3D fabrications. In language learning, MMLs are used for pronunciation practice, listening, presentation skills training, and interactive language learning activities. In addition, they are used for conferences, quizzes and tests, as raining rooms, for voting, online learning, and school management.

Due to the importance of language labs, in particular, a review of the literature has shown some studies that focused on the importance of language labs. For instance, Navas Brenes (2006) found that $68.5 \%$ of the students at the University of Costa Rica think that their English pronunciation has improved a lot as a result of the practice done in the language lab. The researcher added that the language laboratory is very helpful in reinforcing certain areas in which learners are experiencing some difficulty, such as the internalization of correct grammatical structures, pronunciation, and listening comprehension.

\section{K C AL-KINDI CENTER R D FOR RESEARCH AND DEVELOPMENT} Your gateway to world-class research

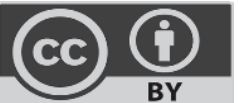

Published by Al-Kindi Center for Research and Development, London, United Kingdom. Copyright (c) the author(s). This open access article is distributed under a Creative Commons Attribution (CC-BY) 4.0 license 
In Soydan's (2018) study, students appreciated computer-learning programs because they could develop computer skills and acquire basic skills by accessing hypermedia/multimedia and game stimulation on computers, which they found user-friendly. The students felt that they made significant progress in their English development because they had support services readily available to them. They could self-pace and self-regulate their learning as well.

In addition, Alexiadis \& Mitianoudis (2013) pointed out that the virtual lab served as a teaching companion for a post-graduate course on multimedia content management, and it enhanced students' comprehension of the material taught.

In India, many students who used the digital MLLs with Computer Assisted Language Learning (CALL) facilities indicated that the MLL sessions helped them boost their self-confidence in writing and speaking in English. Some of the students even suggested that MLL be included in more than one semester's work. Feedback from the students about MLLs was extremely positive (Mohanty, 2009).

In Turkey, college students preferred the lessons taught in the MLLs rather than in class. 84\% of the students liked using the computers in the MLLs. The audio and visual materials in MLLs helped $83 \%$ learn better. They provided them with a variety of resources. $77 \%$ concentrated more and $73 \%$ participated more in MLL learning than in the traditional classroom. 56\% felt that they were learning interactively, which they did not experience in the traditional classroom. The students felt that the lessons were student-centered (Karatay's (2015).

Despite the importance of language labs in developing students' skills in L2, further studies investigated the problems and challenges that students and teachers face in using them. Although the students showed interest in using MLLs, Idri's (2013) reported that they faced problems in using computers. The teachers have never used the labs with their full advanced functions. They were using them as audio material (in listening and phonetics). Large-size classes and the wide number of groups made it challenging for lab teaching to be effective. In Karatay's (2015) study, 65\% of Turkish students reported some very frequent breakdowns in the MLLs and that these breakdowns decreased their motivation.

Furthermore, Mohanty (2009) reported that in most of the oral assignments, technology-in-use was only limited to PowerPoint presentations about business case-studies. She pointed out that for CALL to be successfully implemented, the role of the teacher becomes even more vital. She added that the teacher must work towards effective classroom management that combines accessing multimedia resources along with regular assignments in the form of innovative oral and written tasks. This way, the students will work on authentic tasks through multimedia resources and then engage in real-time discussions and debates that are of interest to them and useful in their daily lives. CALL needs the teacher in the classroom, and the teacher needs CALL to enhance his/her own teaching through ways to which students can easily relate.

To run a language laboratory effectively, Marzuki (2014) advised that there are some aspects that need to be considered such as lab facilities, standard operating rules, students, and lab coordinators. Lab coordinators, in particular, constitute the internal factors that can easily be empowered by the institutions while managing the language lab; in addition to professional development, rewards, and educational management and leadership.

Despite the importance of MMLs for the teaching of interpreting, studies that have investigate the utilization of MLLs are very scant. As for the utilization of MMLs in interpreting instruction, Ping (2014) indicated that the role and meaning of the Internetbased MMLs in interpretation teaching have reflected the change in the talent cultivation concepts and the teaching model from a closed, insular, theoretical concept to a more open, interactive, and practical one. The modern cultivation model for interpreters requires teachers to take full advantage of the Internet-based MMLs by providing more genuine contexts, personal interests, practice opportunities and interpreting strategies. Therefore, it is expected that the appearance and wide application of the Internet-based labs may bring a breakthrough in the limitation of space and time, allowing learners to be more active in learning and using interpreting skills.

Furthermore, the College of Languages and Translation (COLT) at King Saud University, Riyadh, Saudi Arabia prepares translators and interpreters. Some of the courses that the students take are language courses (listening, speaking...etc.) in addition to 4 types of interpreting courses (simultaneous, consecutive, liaison and sight). Instructors have been using traditional language labs in the teaching of listening and interpreting courses for about 3 decades (Al-Jarf, 2015; Al-Jarf, 2007; Al-Jarf, 2000). Recently, COLT has installed 4 new MLLs. The MLLs are currently used for teaching listening. Some instructors at COLT have been facing challenges in how to effectively integrate computer technologies into teaching and learning. Since MMLs are new at COLT and are different from the traditional labs the teachers are familiar with, a study is needed to explore how MMLs are perceived by the COLT faculty and whether MLLS are used in teaching interpreting. Therefore, the purpose of the present study is to find out 
whether the MLLs are feasible for interpreting instruction ay COLT, and to explore the factors that affect the utilization of MLLs in interpreting instruction and the challenges faced in using MMLs in teaching interpreting based on instructors' views.

By investigating the utilization of MLLs in interpreting instruction in Saudi Arabia, the current study starts a new line of research and fills a gap in this area. Findings will be especially useful for college administration who need to know how the digital MMLs are being used, instructors' attitudes toward using the MMLs in teaching interpreting and whether the MMLs are being used to full capacity. Lack of or inadequate utilization of MLLs in teaching interpreting would be a waste of money, resources and time if those MMLs are not being utilized to full capacity. College administrators will become aware of the problems that the instructors are facing in utilizing the new MMLs and they are called for putting the time and effort to solve these problems.

\section{Definitions of Terms}

- Simultaneous Interpreting is a mode of interpreting in which the interpreter interprets at the same time as the speaker as in conference interpreting. The interpreter does not take notes while interpreting.

- Liaison Interpreting is a mode of interpreting in which the interpreter interprets between two people who speak two different languages switching between them. The interpreter listens to speaker 1 language 1, then interprets what he/she said to language 2 for the second speaker. Then listens to speaker 2 in language 2 and interprets what speaker 2 said in language 1 and so on. The interpreter does not take notes while interpreting.

- Consecutive Interpreting is a mode of interpreting in which the interpreter listens to a speaker for a while then interprets what he/she heard, them listens to another segment from the speaker and interprets it. The interpreter can take notes while interpreting.

- Sight Interpreting is a mode of interpreting in which the interpreter has a printed text in hand. He/she glances at the text in the source language (SL) and interprets it into the target language ( $\mathrm{TL}$ ). The interpreter does not take notes while interpreting.

\section{Description of The MLLs at COLT}

Each MLL consists of:

1) A teacher's station.

2) 40 student stations, each having a computer, headsets, and an audio box.

3) The MLL software, which include the following:

A. XClass, a multimedia classroom management software for the computer laboratory. It connects the teacher with students in a networked classroom, enables the students to communicate, learn and collaborate with each other and collaboration between groups. Besides, it acts as a computer monitoring software which helps the teacher supervise students' activities and maintain good order in class. XClass is useful for classroom management, monitoring, and control; (ii) multimedia learning; (iii) group teaching; (iv) quiz and assessment; (v) class organizing and lesson recording; and (vi) the wireless environment. The MML layout, tools and functions of XClass are shown in Images 1, 2, and 3 in the Appendix.

B. A Digital Language Lab Software (DLL): It can be used for pronunciation and listening practice, video presentations, audio discussions and exercises. With the use of DLL, the teacher can easily deliver lessons by various kinds of digital courseware. The contents for DLL are highly flexible. Teaching materials can be tailormade with the help of a language lab content builder. DLL can be applied in the following: Pronunciation practice; (ii) listening practice; (iii) presentation skills training; and (iv) interactive language learning activities (See Image 4 in the Appendix).

C. A Wavelab Audio Editing and Mastering Software: This is a digital audio editor and recording computer software application for Windows and MacOS. It can be utilized in post-processing all types of audio files. It is used for mastering audio, and facilitates editing podcasts (See Image 5 in the Appendix). It has the following features and functions:

- A fully scalable single-window dockable user interface with multiple themes.

- A maximum rate of $384 \mathrm{kHz}$ and bit rate of 32-bit floating point.

- It encodes, imports and allows editing metadata of various audio file formats.

- A Disc Description Protocol (DDP) and a shareable DDP Player.

- An offline loudness analysis.

- Extensive batch processing features and scripting.

\footnotetext{
${ }^{2}$ https://en.wikipedia.org/wiki/WaveLab
} 
- A button to render changes to sound files while they are playing.

- A Spectrum Editor with settings and editing tools.

- An "Audio Inpainting" to recreate missing content.

- Visualizers such as wave scope, phase scope, and a spectrometer.

- A real-time spectrogram for playback and monitored signals.

- Mid/Side viewing, processing, and editing.

- Modern time-stretching and pitch-shifting algorithms.

- Folder watching for automatic offline processing.

- Full integration of external effects hardware.

- A Master Section with effect slots, re-sampling, master level, final effects/dithering, playback processing and speaker configuration.

- Direct exchange and ASIO driver sharing.

- Various effects and processors.

\section{Subjects}

Subjects of the current study consisted of 10 interpreting instructors from the English and French Translation Departments who teach interpreting in English and French. Most of them have a Ph.D., and few have an M.A. degree. An additional instructor who has a Ph.D. in IT and who teaches the Computer Application in Translation courses at COLT participated in the study to give a specialist evaluation of the MMLs. The teaching experience of the subjects ranged between 0 and 25 years.

\section{Instruments}

The subjects were individually interviewed. They were asked open-ended questions about their views of the MLLs at COLT, whether they find them useful for teaching interpreting, which obstacles they have in using the MMLs.

Instructors' responses were classified and grouped into categories and are reported quantitatively and qualitatively.

\section{6- Results}

The interpreting instructors surveyed in the present study indicated that for interpreting, they need to play an audio text and then have the students interpret it either while listening to the text or after they finish listening. The instructor needs to listen to individual students, and the students need to listen to the instructor and each other.

\subsection{Percentage of instructors who uses and do not use the MLLs in teaching interpreting}

Data analysis showed that only $20 \%$ of the instructors at COLT (those who teach simultaneous and on-sight interpreting) fully use the MLLs for teaching interpreting and feel comfortable with them, whereas $80 \%$ of the instructors do not use the MMLs in interpreting instruction. Those who use the MLLs in teaching interpreting reported that they spent hours practicing and solving problems on their own in their free time.

\subsection{Perceived Advantages by Users}

Instructors who use the MLLs in interpreting instruction indicated that the MLLs are interesting. They create a different climate from the traditional classroom and the students enjoy class more. The students listen and concentrate better. The MLLs are good for tests. Students record their interpretation on their MP3 players. Students' recordings are noise-free, i.e., clearer than those on traditional audiotapes. The MP3 player is compact, easier to use than audiotapes. The same MP3 can be used with different instructors and different courses. The instructors can copy files to the PC or a thumb drive and return the MP3 players to the students. Instructors declared:

Nada said: The MLL is good for teaching simultaneous interpreting. I have several texts on a flash memory stick. I send an audio file to all the students who listen to the text and interpret while listening. They record their interpretation using WaveLab.

Nada added: The MLL is not easy to use. I have free time on Mon and Thursday. I used to sit in MLL with the IT professor the whole day and practice using the MLL by trial and error. I practiced for a whole semester.

Ghada asserted: The MLL is good for teaching sight interpreting. I send a text to all the students. They see the text on the screen. They use Wavelab to record their interpretation. I collect the recordings one by one using the teacher's control panel of XClass.

Ghada added: The MLL saves me time. I do not have to make paper copies of the text for each student and different texts for the different course sections. The students cannot write their interpretation down on paper, as they used to do in the old language labs. 


\subsection{Perceived Challenges by Non-users}

Interviews showed that $80 \%$ of the instructors at COLT do not use the MLLs for teaching interpreting. None of the French instructors uses the MMLs for teaching interpreting. The instructors believe that MLLs are good for teaching listening skills, not consecutive and liaison interpreting. They use the MLLs as a classroom only. They record a text on a flash drive or MP3 players at home, play it in the MML, and use the speakers only. They do not use the lab software and hardware.

Results of the interviews revealed the following issues that affect lack of utilization of the MLL's in teaching interpreting:

1) Instructor-related Issues

Many instructors find the MLL frustrating. The declared that they are not used to it. They believe that they do not need computers for the interpreting courses. They prefer the old language labs as they are easy to operate, whereas the MLLs are too complicated to operate. The MLLs have too many functions, lights and icons that they do not know how to use (See Images 2 and 3).

2) Student-related issues

Some instructors reported that they waste time teaching the students how to use the MLL. There are too many buttons for the students. All the students have to turn on their PCs in order to start the MLL. Some students come late. Others enter their filename in Arabic or make mistakes in entering filenames. Sometimes they lose their files. At other times they record multiple files (14 files) and the instructors has to listen to 14 files to give a grade. Some students have difficulty sending their audio files to the instructors and instructors have difficulty collecting all of the students' audio files. The files have to be collected one at a time. The students do not start and do not respond at the same time. Instructors commented:

Suna: The MLL is psychologically threatening for the students, especially during exams.

Taline: The recording quality differs from one student to another.

3) Perceived MLL Seating Capacity, Software and Hardware Problems

The instructors indicated that there are several hardware and software problems in the MLL. The MLL is not user friendly. The MLL manual is not helpful and is difficult to follow. They do not know how to use the intercom. All the student booths have to be on, in order to send a file to all the students, i.e., all the students should be present. Some students' booths (workstations) work, others do not. If a student steps on a cable, the booth stops working. Some instructors do not receive any files from the students, i.e., "file-transfer" problem. The software is not properly functional, when students send their audio files to the instructor, some files get lost. The WaveLab filename has to be in English, if one letter is in Arabic the computer does not recognize it. Instructors waste some of the class time fixing problems. Some instructors reported:

Dalal: I have 160 students in my class and have to divide the students into groups to use the MLL, because the MLL has 40 booths only, arranged into 2 groups. The instructor can work with one group at a time, not both. When I am working with one group, the students in the other group have nothing to do.

Nadia: There is no way for me to know if a student is concentrating or if she is busy with something else such as browsing social media, as all booths are connected to the internet.

4) Technical support issues

The instructors revealed that there is no technical support staff on-call when a problem occurs. They need a technical support staff who is available in the college all the time. They need a technical support staff to check and test the booths and the system before and after each class session. When the instructors complain to the Company in charge of the MLLs, the Company ask them to set an appointment for a training session in the late afternoon, after class hours, but some instructors are unwilling to come in the late afternoon for further training after a full busy day. Some instructors said:

Maha: I need to start more workstations than the number of students attending the class session, so that if there is a technical problem, I can change the student's workstation.

Fatimah: After a long day of teaching, it is difficult for me to come back to the university in the late afternoon to attend a training or briefing session regarding the MMLs.

Ruba: Since there is no periodic maintenance for the MLLs, it is embarrassing when I try to play an audio and it does not work. 


\subsection{What the IT specialist thinks}

The instructor who has a Ph.D. in IT reported that the MLLs have no problem. They just use new technology with which the instructors are not familiar and which they cannot figure out on their own. The MLL manual is easy, straightforward but has too many details. She added that the instructors need training. The Company offered training for a month with the help of a technician. Some instructors attended one training session only, but the majority did not attend any training sessions.

\section{Discussion, Recommendations}

The MLL is a new technology that requires a change in how interpreting courses are taught. It seems that there is resistance on the part of the instructors as they have to leave their comfort zone, i.e., using the old traditional labs for a long time. They feel intimidated by this new technology. They have negative attitudes towards the MLsL. A young instructor who has just graduated and joined the college has the same attitude and asserted that she did not try any MLL. She mimics what she hears from her colleagues without even trying. Instructors listen to and pass on negative thoughts and attitudes.

The problems that the instructors reported in the present study are consistent with findings reported by some prior studies such as Idri's (2013) who indicated that the students were facing problems in using the computers and that the advanced functions of the language labs were not being fully used by the instructors. The instructors are using them as an audio material (in listening and phonetics). Idri added that large-class sizes make it challenging for the language lab to be effective.

The technical issues that instructors in the present study are experiencing are also similar to those reported by Karatay (2015), who found that $65 \%$ of Turkish students experienced frequent breakdowns in the MLLs and that these breakdowns decreased the students' motivation.

To help interpreting instructors adapt to the new MLL technology, the study recommends giving the instructors a normalization period and a chance to explore the MLL at their own pace, practice on their own, and get used to the MLL hardware and software. Hands on practice on a one-to-one basis, not as a group of spectators, is needed. Instructors who are competent in using the MLLs in interpreting and even listening courses may train their colleagues, answer their questions, and solve the problems they face. They need to listen to each other's successful experiences to overcome their fears and anxiety, and to be motivated to use the MLLs in interpreting instruction. Availability of technical support staff on site is crucial. The Deanship of eLearning, in charge of the MLLs, should have live online support, as it is the case with the Blackboard Learning Management System.

Moreover, the study recommends applying the active language-learning approach proposed by Helmer (2019), in which students interested in learning a new language or improving their English thrive when labs are transformed into active learning spaces. In interpreting classes, it is not sufficient for the students to listen to an audio in the source language and translate it to the target language. They should have an active role in interpreting, such as role-playing. They can come up with their own texts, then engage in interpreting, in pairs in consecutive interpreting, or groups of three in liaison interpreting, where one student acts as the interpreter, the other two act as the guest speakers.

Finally, to have a global view of the feasibility of using the MMLs in interpreting courses at COLT, the study recommends that researchers in Saudi Arabia conduct follow-up studies on the utilization of MLLs in interpreting after re-training the instructors and introducing them to interactive interpreting activities. The author also recommends exploring translation students' experience with the MMLs and whether they find practicing interpreting skills in the MLLs beneficial or not and exploring the problems they face.

Conflicts of Interest: The authors declare no conflict of interest.

Funding: This research received no external funding. This article was fully sponsored by the author.

\section{References}

[1] Al-Jarf, R. (2015). Consecutive interpreting teaching guide. Retrieved from https://www.researchgate.net/publication/281003347_Consecutive_Interpreting_Teaching_Guide

[2] Al-Jarf, R. (2007). How to teach liaison interpreting. Conference on the Foundations for a Pedagogy of Arabic Translation. University College Francisco Ferrer, Brussels, Belgium. October 18-20.

[3] Al-Jarf, R. (2000). Bridging the gap between teacher and learner in liaison interpreting. TESOL Arabia' 2000 Conference titled "Bridging the Gap between Teacher and Learner". Al-Ain, UAE, April 12-14.

[4] Helmer, J. (2019). Active learning in the language lab. Retrieved from https://universitybusiness.com/active-learning-in-the-language-lab/

[5] Huang, S. J. \& Liu, H. F. (2000). Communicative language teaching in a multimedia language lab. The Internet TESL Journal, 6, 2. http://iteslj.org/Techniques/Huang-CompLab.htm 
[6] Idri, N. (2013). Using multimedia labs in enhancing EFL Students' research methods. Multilinguales, 1, 80-93. https://doi.org/10.4000/multilinguales.3108

[7] Karatay, Y. (2015). An investigation of a multimedia language lab project in Turkish state universities. Paper presented at the EUROCALL Conference, Padova, Italy, Aug 26-29, 2015. ERIC ED564221.

[8] Marzuki, M. (2014). Managing an effective english language laboratory in a polytechnic. Studies in English Language and Education, 1(2), 106-115.

[9] Alexiadis, D. S. \& Mitianoudis, N. (2013). MASTERS: A virtual lab on multimedia systems for telecommunications, medical, and remote sensing applications. IEEE Transactions on Education, 56(2), 227-234.

[10] Mohanty, S. (2009). Digital language labs with CALL facilities in India: Problems and possibilities. Reflections on English Language Teaching, 8(1), 65-72.

[11] Navas Brenes, C. A. (2006). The language laboratory and the efl course. Actualidades investigativas en educación, 6(2), 1-25. Retrieved from https://www.redalyc.org/pdf/447/44760202.pdf

[12] Ping, L. (2014). The Role and Meaning of the Internet-based Multimedia Labs in Interpretation Teaching. Retrieved from https://en.cnki.com.cn/Article en/CJFDTotal-YYXT200900029.htm

[13] Soydan, D. (2018). Adult learners' experience with immediate intervention in a self-regulated learning environment. D.Ed. Dissertation. Capella University. ERIC ED586689.

\section{Appendix}

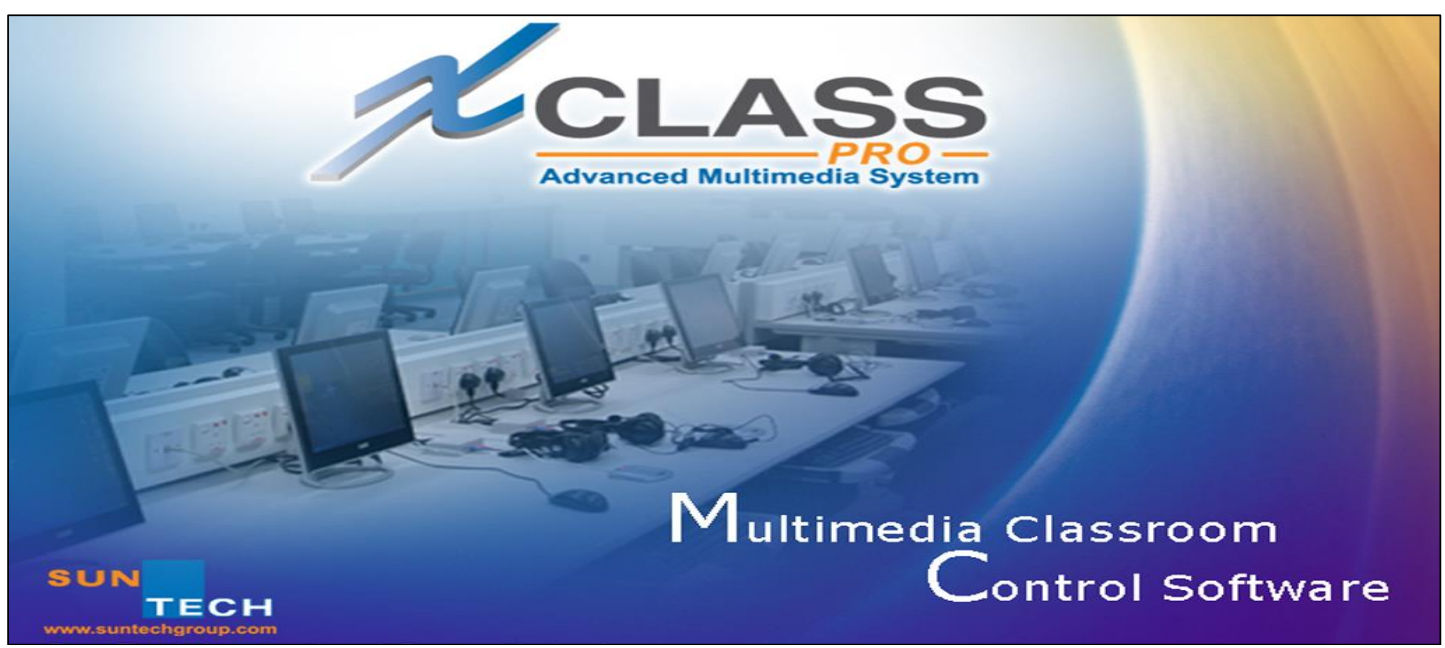

a) Image 1: Multimedia Language Lab Layout

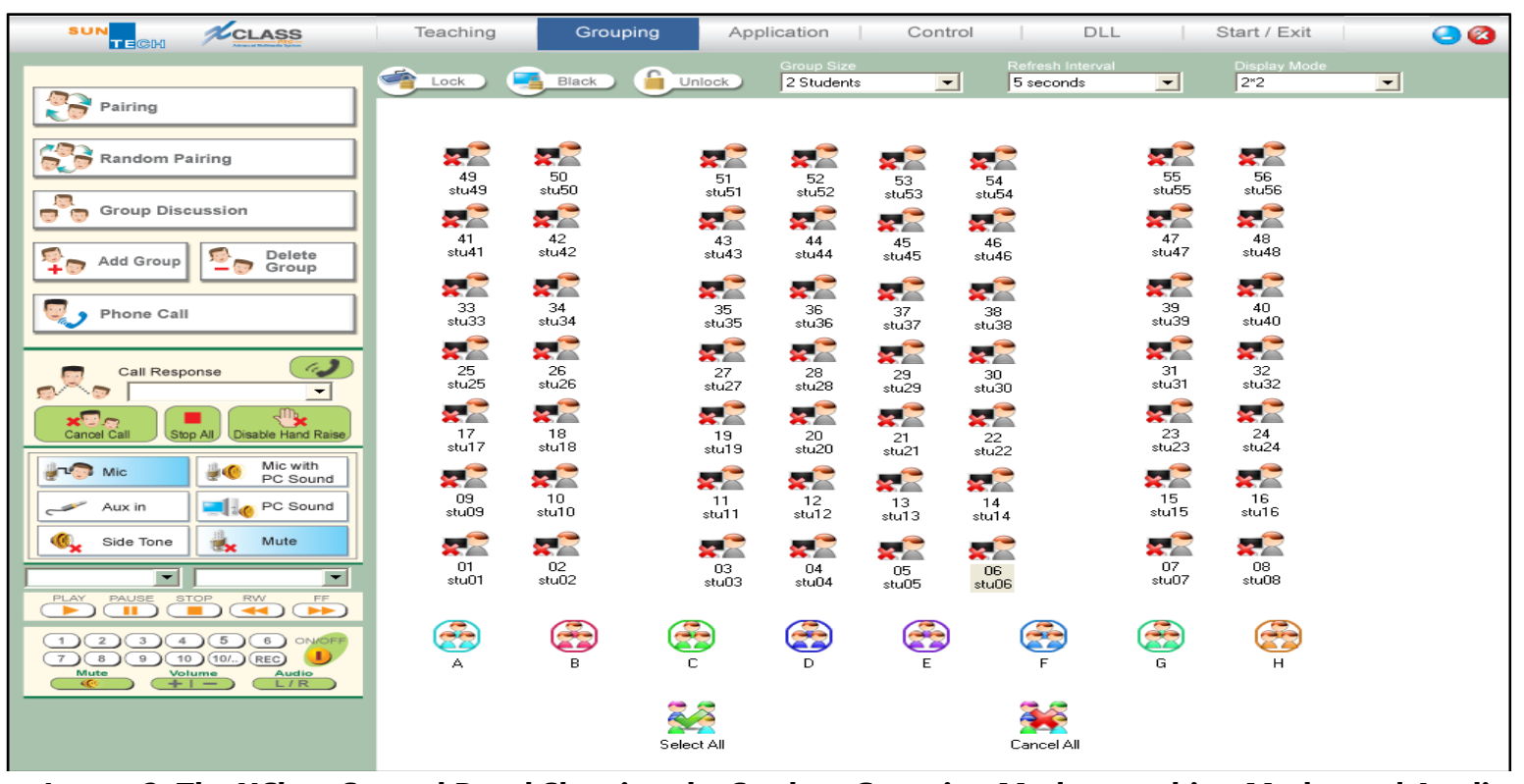

b) Image 2: The XClass Control Panel Showing the Student Grouping Modes, teaching Modes and Applications usedImages 3: Tools and Functions in the XClass Software 


\section{A. Tools to Enhance Class Interaction}

Teacher Show \& Student Show

- Broadcasts teacher's or selected student's screen and voice to student PCs

Class Grouping

- Pairing, random pairing and group discussion are available Intercom

- Allows teacher to proceed real-time intercom with selected student Instant Phone Call

- Allows discussion between students

File Transfer

- Transfers to or receive files/ folders from any selected student Multimedia Learning

- Allows to broadcast 9 different videos simultaneously by XPLAYER

Class Merging

- Allows teacher to merge classes by just a few clicks

Remote Login

- Allows teacher to logon student PC remotely
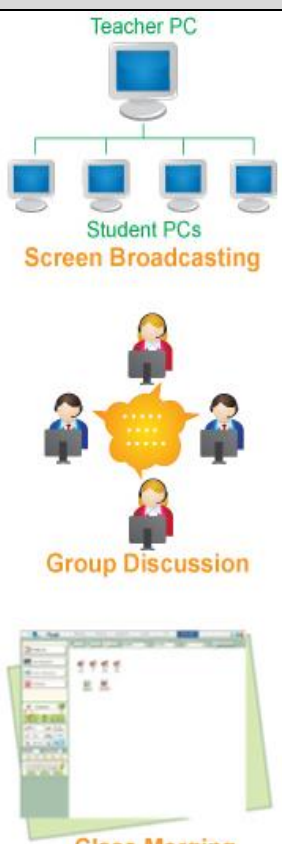

Class Merging

\section{B. Monitoring Students' Learning Progress}

Student Screen Monitor \& Voice Monitor

- Simultaneously monitors students' screens

- Monitors multiple audio sources on student PCs Application Monitor

- Monitors students' processing tasks Keyboard Monitor

- Allows teacher to monitor students' typing Student Help

- Aware of student active requests and provide assistance if necessary Remote Aid

- Remote control of students, PCs to give instructions

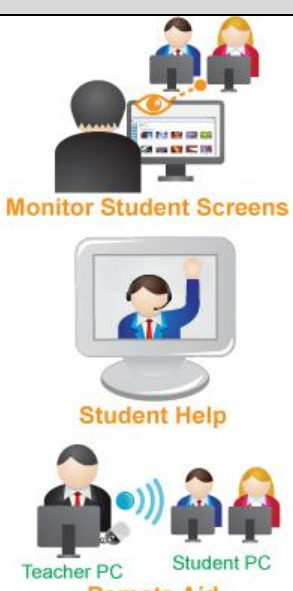

\section{Controlling Students on Inappropriate Activities}

Black \& Lock Screen

- Locks keyboard and mouse of student PCs

Disable Web

- Completely/Selectively blocks students' web-browsing activities Disable USB

- Allows teacher to enable/ disable the use of USB storage on selected Student PC Printer Management

- Allows teacher to resume/ pause/ disable students' printing jobs
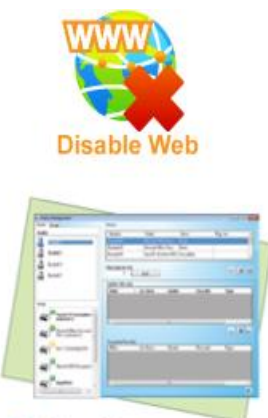

Printer Management 


\section{Creating Comprehensive Quizzes}

Question Editor

- Allows teacher to prepare quiz with 6 different question styles including Multiple Choices, Fill in the Blank, True or False, Matching, Ordering and Long Question with ease

- Supports text, picture, audio and video based questions

Quiz Management

- Divides students into different groups, and their results could be presented in group approach

- Collects paper automatically/ manually

Auto Marking \& Reporting

- Performs auto-marking and provide instant result

- Reports can be generated automatically and presented in Excel and csv formats

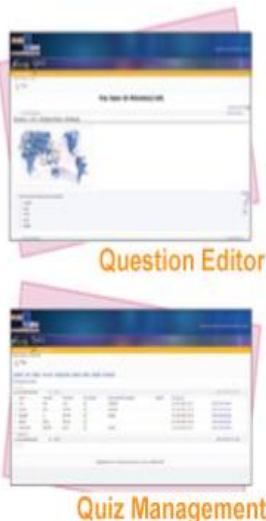

Quiz Management

\section{E. Scheduling, Organizing and Recording Lessons}

Lesson Reminder

- Allows teacher to organize lessons, quizzes and teaching activities in a well-presented manner

Lesson Recorder

- Records teacher's PC screen and audio during lesson

- Allows students to review the lesson even they have missed
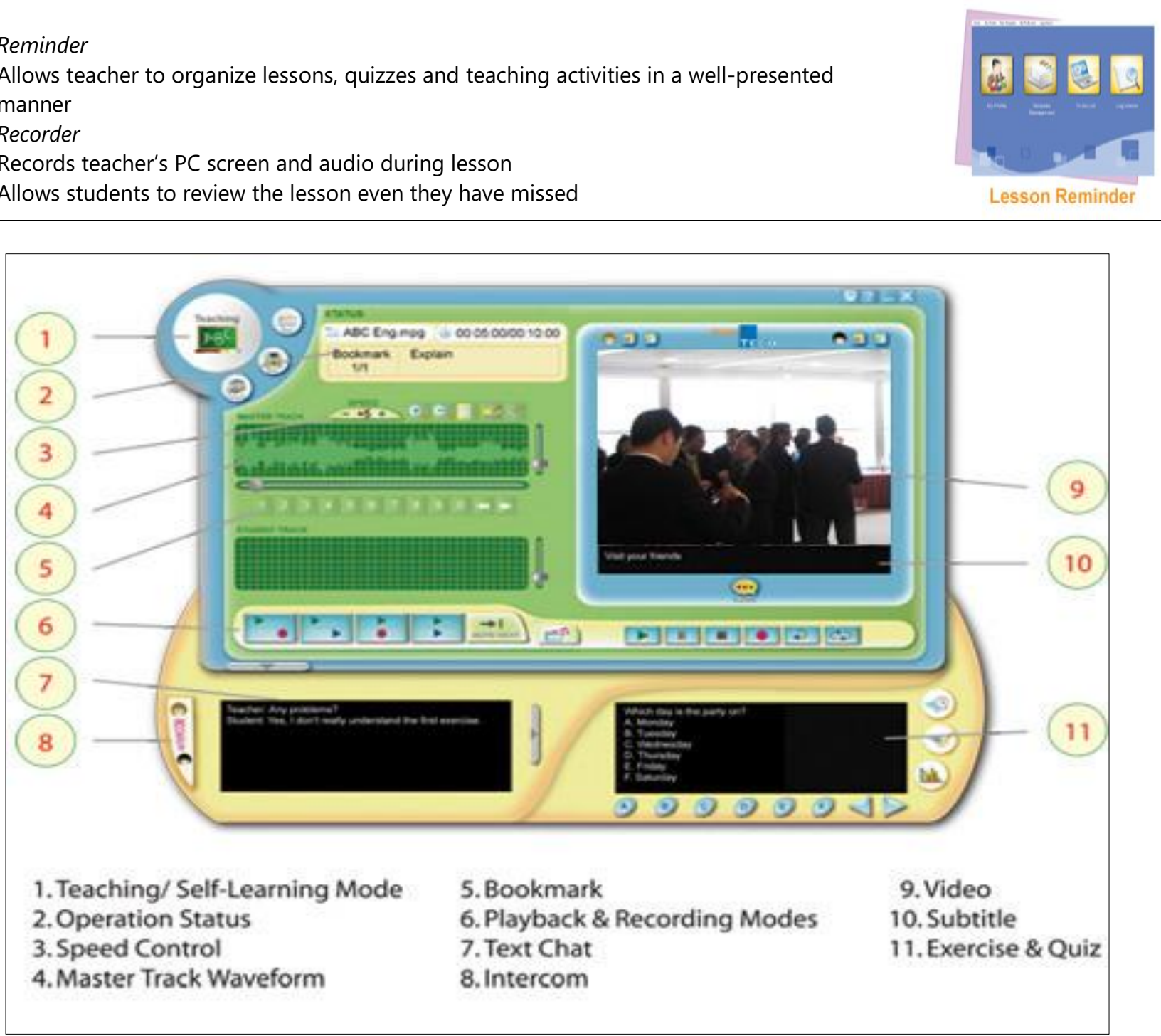

c) Image 4: Features and Tools (Audio + Video + Text) of the DLL Software System 


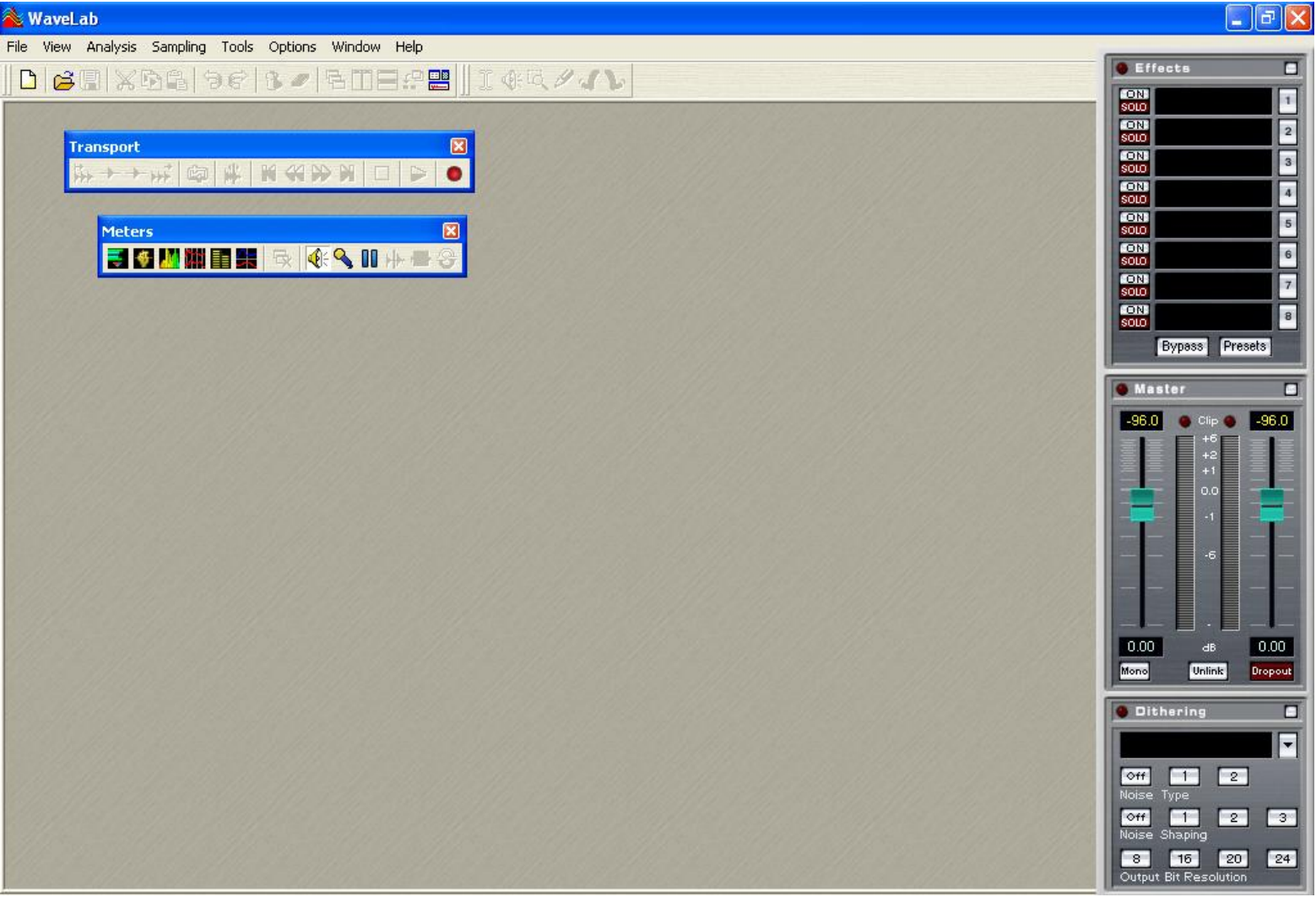

d) Image 5: WaveLab Mastering and Audio Editing Software 